\title{
Quantification, description and international comparison of antimicrobial use on Irish pig farms
}

Lorcan O’Neill ${ }^{1,2^{*}}$ D, Maria Rodrigues da Costa ${ }^{1,2}$, Finola C. Leonard², James Gibbons ${ }^{3}$, Julia Adriana Calderón Díaz ${ }^{1}$, Gerard McCutcheon ${ }^{1,4}$ and Edgar García Manzanilla $a^{1,2}$

\begin{abstract}
Background: There is concern that the use of antimicrobials in livestock production has a role in the emergence and dissemination of antimicrobial resistance in animals and humans. Consequently, there are increasing efforts to reduce antimicrobial use (AMU) in agriculture. As the largest consumer of veterinary antimicrobials in several countries, the pig sector is a particular focus of these efforts. Data on AMU in pig production in Ireland are lacking. This study aimed to quantify AMU on Irish pig farms, to identify the major patterns of use employed and to compare the results obtained to those from other published reports and studies.

Results: Antimicrobial use data for 2016 was collected from 67 Irish pig farms which represented c. 35\% of national production. The combined sample population consumed $14.5 \mathrm{t}$ of antimicrobial by weight of active ingredient suggesting that the pig sector accounted for approximately 40\% of veterinary AMU in Ireland in 2016. At farm level, median AMU measured in milligram per population correction unit (mg/PCU) was 93.9 (range: 1.0-1196.0). When measured in terms of treatment incidence (TI200), median AMU was 15.4 (range: 0.2-169.2). Oral treatments accounted for $97.5 \%$ of all AMU by weight of active ingredient and were primarily administered via medicated feed to pigs in the post weaning stages of production. AMU in Irish pig production in 2016 was higher than results obtained from the national reports of Sweden, Denmark, the Netherlands and France but lower than the United Kingdom.

Conclusions: Pig production in Ireland is an important consumer of veterinary antimicrobials. The quantities and patterns of AMU on Irish pig farms are comparable to pig production in other European countries but higher than some countries with more advanced AMU reduction strategies. This AMU is characterised by a high proportion of prophylactic use and is primarily administered to pigs post weaning via medicated feed. Further studies to better understand the reasons for AMU on Irish pig farms and strategies to improve health among weaner pigs will be of benefit in the effort to reduce AMU.
\end{abstract}

Keywords: Antimicrobial use, Pigs, Ireland

\footnotetext{
* Correspondence: Iorcan.oneill@ucdconnect.ie

'Pig Development Department, Teagasc, The Irish Food and Agriculture Authority, Moorepark, Fermoy, Co Cork, Ireland

${ }^{2}$ School of Veterinary Medicine, University College Dublin, Belfield, Dublin 4, Ireland

Full list of author information is available at the end of the article
}

(c) The Author(s). 2020 Open Access This article is licensed under a Creative Commons Attribution 4.0 International License, which permits use, sharing, adaptation, distribution and reproduction in any medium or format, as long as you give appropriate credit to the original author(s) and the source, provide a link to the Creative Commons licence, and indicate if changes were made. The images or other third party material in this article are included in the article's Creative Commons licence, unless indicated otherwise in a credit line to the material. If material is not included in the article's Creative Commons licence and your intended use is not permitted by statutory regulation or exceeds the permitted use, you will need to obtain permission directly from the copyright holder. To view a copy of this licence, visit http://creativecommons.org/licenses/by/4.0/ The Creative Commons Public Domain Dedication waiver (http://creativecommons.org/publicdomain/zero/1.0/) applies to the data made available in this article, unless otherwise stated in a credit line to the data. 


\section{Background}

In the global effort to combat antimicrobial resistance a 'One Health' approach, encompassing human and animal health as well as the environment, has been proposed [1, $2]$. In common with other countries, Ireland has implemented its own One Health action plan, iNAP (Ireland's National Action Plan against Antimicrobial Resistance) [3]. Efforts to monitor and ultimately reduce antimicrobial use (AMU) in livestock production are important components of such plans [4]. These efforts are necessary as the use of antimicrobials in livestock production has been linked to the emergence and dissemination of antimicrobial resistant bacteria in animals and humans [5-7].

Pig production is the highest consumer of veterinary antimicrobials in many countries [8-10]. Until recently, only a limited number of countries, such as Denmark [8] and the Netherlands [9], monitored AMU stratified by species. Currently, however, many countries have followed the example of Denmark and the Netherlands and have developed, or are developing, their own AMU databases [11]. Data from some of these schemes were published recently, for example, from Germany [12] and Belgium [10]. Elsewhere, data on AMU in pig production derives from a limited number of cross-sectional studies in countries such as Canada [13, 14], Austria [15], France [16, 17], Spain [18, 19] and Belgium [20] as well as two pan European studies [21, 22]. Several of these studies show that the majority of antimicrobials are administered orally, as group treatments, are frequently applied for prophylactic (to prevent disease) or metaphylactic purposes (to treat a group containing some diseased animals) and primarily administered to pigs post weaning.

The pig population in Ireland comprises approximately 140-150,000 breeding animals and 1.5-1.6 million fattening pigs and is the third largest livestock sector after dairy and beef $[23,24]$. To date, data on the use of antimicrobials in Irish pig production are lacking but is reputed to be high [25].

The objectives of this study were 1) to quantify antimicrobial use on Irish pig farms, 2) to determine the major patterns of use employed, and 3) to compare the results to those from other published reports and studies.

\section{Methods}

\section{Farm selection}

A cross-sectional study was conducted on a convenience sample of 67 Irish pig farms to investigate antimicrobial usage. The participating farms were clients of the Teagasc (The Agriculture and Food Development Authority) farm advisory service ${ }^{1}$ which is available to all Irish pig farms. In 2017, the Teagasc farm advisory service

\footnotetext{
${ }^{1}$ https://www.teagasc.ie/animals/pigs/
}

included 107 pig farms, representing over 77,000 sows (c. $50 \%$ of national herd); all farms were invited to participate in the study and 67 agreed to co-operate. All farms operated a farrow-to-finish system. Farrow-tofinish enterprises account for virtually all of pig production in Ireland [26].

\section{Data collection}

Farms were visited between September 2017 and October 2018 to collect detailed antimicrobial use data for the 2016 calendar year. The farmers were asked to provide prescription and or invoice data in order to determine the amounts of antimicrobials used. Farmers were asked to indicate which stages of production each antimicrobial preparation was used in and whether any prophylactic or metaphylactic use occurred during the year. Population, feed consumption, performance and production data were obtained from the Teagasc eProfit Monitor (ePM) database to which farmers submit their data quarterly. Farmers not using the ePM $(n=8)$ were asked to provide the relevant data directly.

\section{Quantification of antimicrobial use}

The amounts of active ingredient in each antimicrobial product were determined according to the protocols outlined by the European Medicines Agency (EMA) for its European Surveillance of Veterinary Antimicrobial Consumption (ESVAC) project [27]. Conversion factors for prodrugs (such as procaine benzylpenicillin) and international units (I.U.) were also obtained from the ESVAC protocol.

\section{Medicated feed}

Antimicrobial oral premixes are remedies specifically intended for use in medicated feed [28] and thus are distinct from oral remedies intended for use in water or those added to feed as a 'top dressing.' While medicated feeds may include other types of medication (for example, anthelmintics, anti-inflammatories or zinc oxide), in this article, the term 'medicated feed' will refer to feeds or diets including antimicrobial oral premixes. Specific diets are fed during each stage of pig production and any of these diets may be medicated with antimicrobials. The stages of production on Irish pig farms are summarised as follows: piglets are generally weaned at around 28 days, the weaned piglets remain in the weaner stage, which, on Irish farms is typically split into first and second stages, for up to 9 weeks and, thereafter, the pigs stay in the finisher stage until slaughter, at around 24 weeks of age. A creep or pre-starter diet is provided to piglets in the farrowing house; after weaning, the pigs are typically fed a starter diet for 7-14 days, followed by a link diet for another 7-14 days and then a weaner diet for the remainder of the weaner stage; finally, finisher 
pigs are fed a finisher diet. Sows are fed specific diets depending on whether they are in gestation or lactation. The amount of medicated diet used in each category for each antimicrobial included was determined by 1) consulting data submitted to the ePM, 2) invoice records, or 3) data provided directly by the farmer. To calculate the amounts of antimicrobial administered in medicated feed the following formula was used:

weight of medicated feed $(\mathrm{kg})$ $\times$ inclusion rate of active ingredient $(\mathrm{mg} / \mathrm{kg})$

The inclusion rate was expressed in terms of $\mathrm{mg}$ of antimicrobial per $\mathrm{kg}$ of medicated feed (e.g. chlortetracycline $300 \mathrm{mg} / \mathrm{kg}$ ). This calculation was performed for every combination of diet and antimicrobial inclusion rate.

\section{Other oral remedies and parenteral preparations}

Complete prescription records for other oral remedies and parenteral preparations were not available for five farms. In these cases, missing values for each antimicrobial product used on the farm were imputed based on either the estimate of use provided by the farmer or the median value of use on the other farms using the same product. To calculate the amounts of antimicrobials administered by other routes of administration the following formula was used:

number of packs $\times$ pack size $(\mathrm{g}$ or $\mathrm{ml})$ $\times$ strength $(\mathrm{mg} / \mathrm{ml}$ or $\mathrm{mg} / \mathrm{kg})$

This calculation was performed for each preparation of each active ingredient.

\section{Treatable kilograms}

In order to adjust for differences in potency between the various active ingredients, the amounts used of each antimicrobial were adjusted to 'treatable kilograms' (TK) based on the Defined Daily Dose for the given active ingredient $\left(\mathrm{DDD}_{\mathrm{vet}}\right)$ as defined by ESVAC [29]. 'Treatable kilograms' represents the number of kilograms of pig which can be treated with the given amount of antimicrobial if the Defined Daily Dose is used. For example, $20 \mathrm{mg}$ of marbofloxacin $\left(\mathrm{DDD}_{\mathrm{vet}}=2 \mathrm{mg} / \mathrm{kg}\right)$ can treat $10 \mathrm{~kg}$ of pig. This calculation is based on the definition outlined by the Netherlands Veterinary Medicines Institute [9]:

$$
\begin{aligned}
& \text { treatable kilograms }\left(\mathrm{TK}_{\mathrm{DDDvet}}\right) \\
& =\frac{\text { amount of antimicrobial used }(\mathrm{mg})}{\mathrm{DDD}_{\text {vet }}(\mathrm{mg} / \mathrm{kg})}
\end{aligned}
$$

Two antimicrobials, tulathromycin and tildipirosin, do not have an assigned $\mathrm{DDD}_{\text {vet; }}$ the defined daily animal doses (DDDA) and long acting factors defined by Postma et al. were used [30].

\section{Indicators of antimicrobial use at farm level}

The milligram per population correction unit (mg/PCU) was developed by the EMA and is the indicator of antimicrobial consumption used in the ESVAC reports on sales of veterinary antimicrobials in the European Union (EU) and European Economic Area (EEA) [31]. The mg/ PCU uses the weight of active ingredient as the numerator while the population correction unit (PCU) is used as the denominator. The PCU assigns a standardised weight to each species and to sub-categories where applicable [31]. The calculation of $\mathrm{mg} / \mathrm{PCU}$ for pigs is further described in Additional file 1.

Treatment incidence (TI) represents the percentage of pigs in a stage of production treated with a dose of antimicrobial each day or, the percentage time of the period at risk for which a pig was treated. The TI indicator, as defined for pigs by Timmerman et al. [32] and adapted by Sarrazin et al. [22], was calculated as follows:

$$
\begin{gathered}
\mathrm{TI}_{\mathrm{DDDvet}}=\frac{\text { amount of antimicrobial used }(\mathrm{mg})}{\mathrm{DDD}_{\text {vet }}(\mathrm{mg} / \mathrm{kg}) \times \mathrm{kg} \text { of animal at risk }(\mathrm{kg}) \times \text { number of days at risk }} \\
\times 100 \text { animals at risk }
\end{gathered}
$$

The numbers of animals at risk and numbers of days at risk for each category were derived from ePM or farm data. For a detailed description of the TI calculation see Additional file 1 . The $\mathrm{TI}_{\mathrm{DDDvet}}$ was calculated for each antimicrobial per age category (piglet, weaner, finisher and sow). Finally, the TI for piglets, weaners and finishers were combined and recalculated as a standardised TI200 using the formula defined by Sjölund et al. [21]:

$$
\begin{aligned}
\mathrm{TI} 200=\frac{\mathrm{TI}_{\text {piglet }} \times \text { suckling period }}{}+\mathrm{TI}_{\text {weaner }} \times \text { weaner period }+\mathrm{TI}_{\text {finisher }} \times \text { finishing period } \\
\text { total rearing period } \\
\times \frac{200(\text { standard lifespan })}{\text { total rearing period }}
\end{aligned}
$$

\section{Comparison to AMU in selected European countries}

Data concerning the weight of antimicrobials used or sold in pig production during 2016 were extracted from the national reports of the following countries: Sweden [33], Netherlands [34], Denmark [35], and France [36]. The value obtained was divided by the corresponding PCU for pigs extracted from the ESVAC report for 2016 [37] to calculate consumption in mg/PCU. Antimicrobial use in pigs in the United Kingdom (UK) for 2016 was based on data collected by the e-medicine book for pigs (eMB pig) and was reported in $\mathrm{mg} / \mathrm{PCU}$ [38].

To allow a further comparison with the national AMU consumption reports of Denmark and the Netherlands for 2016, the total AMU of the combined population of the sample farms was recalculated using their respective 
indicators. The DAPD, defined as the 'proportion of population in treatment per day', is the indicator used to report AMU at national level in Demark [8] and the DDDA $_{\text {NAT }}$ (Defined Daily Dose Animal) is used in the national reports of the Netherlands [9]. For further details, see Additional file 1 .

\section{Data processing}

All data were entered into a Microsoft $^{\circ}$ Excel 365 spreadsheet. Calculations and descriptive statistical analysis were carried out using Microsoft ${ }^{\circ}$ Excel and $\mathrm{R}$ version 3.4.2 [39]. Data visualisation was carried out using the R packages ggplot2 [40] and VennDiagram [41].

\section{Results}

\section{Farm characteristics}

The 67 farms included in the study had a median herd size of 528 sows (range 110-3000) and median production of 12,429 pigs for slaughter (range 2600-58,300) during 2016. The combined population of the 67 farms was approximately 48,000 sows and thus represented around 35\% of the national herd in 2016 [42].

\section{Overview of antimicrobial consumption}

The total estimate of antimicrobial use on the 67 study farms during 2016 by weight of active ingredient was $14.5 \mathrm{t}$, comprising a total of 19 different antimicrobial compounds. Table 1 summarises the patterns of antimicrobial use and shows the breakdown of use by route of administration for each antimicrobial class. The majority of antimicrobials, representing $97.5 \%$ of the weight of active ingredient and $93.9 \%$ of treatable kilograms $\left(T K_{\text {DDDvet }}\right)$, were administered orally and mainly in medicated feed. One farm did not use any oral treatments while all farms used injectable treatments. Tetracyclines, potentiated sulphonamides, macrolides and penicillins accounted for almost all antimicrobials consumed (98.2\% of the weight of active ingredient; $94.3 \%$ of $\left.\mathrm{TK}_{\text {DDDvet }}\right)$. The use of tetracyclines in medicated feed had the highest impact on consumption, was observed on $64.1 \%$ of farms and accounted for more than half all AMU by weight of active ingredient (32.4\% of $\left.\mathrm{TK}_{\mathrm{DDDvet}}\right)$. Some patterns of use, while not impacting greatly on overall consumption, were observed on most farms. For example, all farms used injectable penicillins (amoxycillin or benzylpenicillin) and $83.6 \%$ of farms used injectable fluoroquinolones (enrofloxacin and marbofloxacin). Antimicrobial use was highest in weaner pigs, which accounted for $69.7 \%$ of AMU by weight of active ingredient and $63.2 \%$ of $\mathrm{TK}_{\mathrm{DDDvet}}$. Finisher pigs accounted for $25.4 \%$ of AMU by weight of active ingredient and

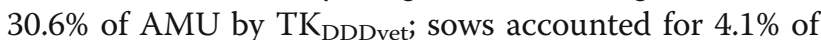
AMU by weight of active ingredient and $3.5 \%$ of AMU by $\mathrm{TK}_{\mathrm{DDDvet}}$ and piglets accounted for $0.9 \%$ of $\mathrm{AMU}$ by weight of active ingredient and $2.7 \%$ of AMU by

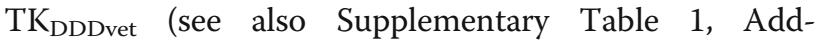
itional file 2). The indicators of AMU at farm level in $\mathrm{mg} / \mathrm{PCU}$ and treatment incidence (TI200) are summarised in Table 2.

\section{Antimicrobial use in medicated feed}

Figure 1 summarises AMU in medicated feed for each diet category. Sixty-one farms (91\% of the sample) used medicated feeds during 2016 and this accounted for $89.1 \%$ of all AMU by weight of active ingredient $(83.1 \%$ of $\mathrm{TK}_{\mathrm{DDDvet}}$ ). The percentage of farms medicating each diet category and the patterns of use employed are illustrated in Fig. 2. The majority of medicated feed was provided to pigs in the post weaning stages of production and accounted for $66.3 \%$ of all AMU by weight of active ingredient $\left(58.6 \%\right.$ of $\left.\mathrm{TK}_{\text {DDDvet }}\right)$. Most farms $(88.1 \%$ of sample) medicated at least the starter and/or link diets, meaning that most pigs in the study were treated with antimicrobials during the first 7-21 days post weaning. Thirty-five farms (52.2\% of sample) also provided medicated creep diets to piglets in the farrowing house. Antimicrobial use in the starter and link diets accounted for $14.8 \%$ of weight of active ingredient and $19.0 \%$ of $\mathrm{TK}_{\mathrm{DDDvet}}$. Regarding the active ingredients used, there was more variation in these diets compared to the other diet categories; tetracyclines, potentiated sulphonamides, macrolides, penicillins and aminoglycosides were all commonly used. Medicated weaner diets, mainly with tetracyclines or potentiated sulphonamides, were used on 38 farms ( $57.7 \%$ of sample). They generally followed medication in the starter and/or link diets (see Fig. 2) and accounted for $50.5 \%$ of total AMU by weight of active ingredient (39.6\% of TK $\left.K_{\mathrm{DDDvet}}\right)$. Antimicrobial use in medicated feed in the weaner stages was generally for prophylactic purposes; farms applied the same protocol to every batch produced during the year. In the finisher stage, medicated feed was used on 16 farms (23.9\% of sample) and contributed to $20 \%$ of overall use by weight of active ingredient (22.3\% of $\left.\mathrm{TK}_{\mathrm{DDDvet}}\right)$. Tetracyclines and macrolides were the most commonly used classes in finisher diets, however, heavy use of sulfadiazine and trimethoprim on one farm meant it was the antimicrobial with the highest consumption in this category. Routine prophylaxis was less common and practised by six farms. In addition, $25.4 \%$ of farms provided medicated feed to sows, typically once or twice per year for a period of $7-$ 10 days. The antimicrobials used in medicated feed varied within the farm, between diets and over time. Half of all farms used 3 or more antimicrobials (see Supplementary Figure 1, Additional file 2). This reflects the fact that some farms used combinations of antimicrobials, either combination products or custom formulations; that some farms changed treatment regime during the year 


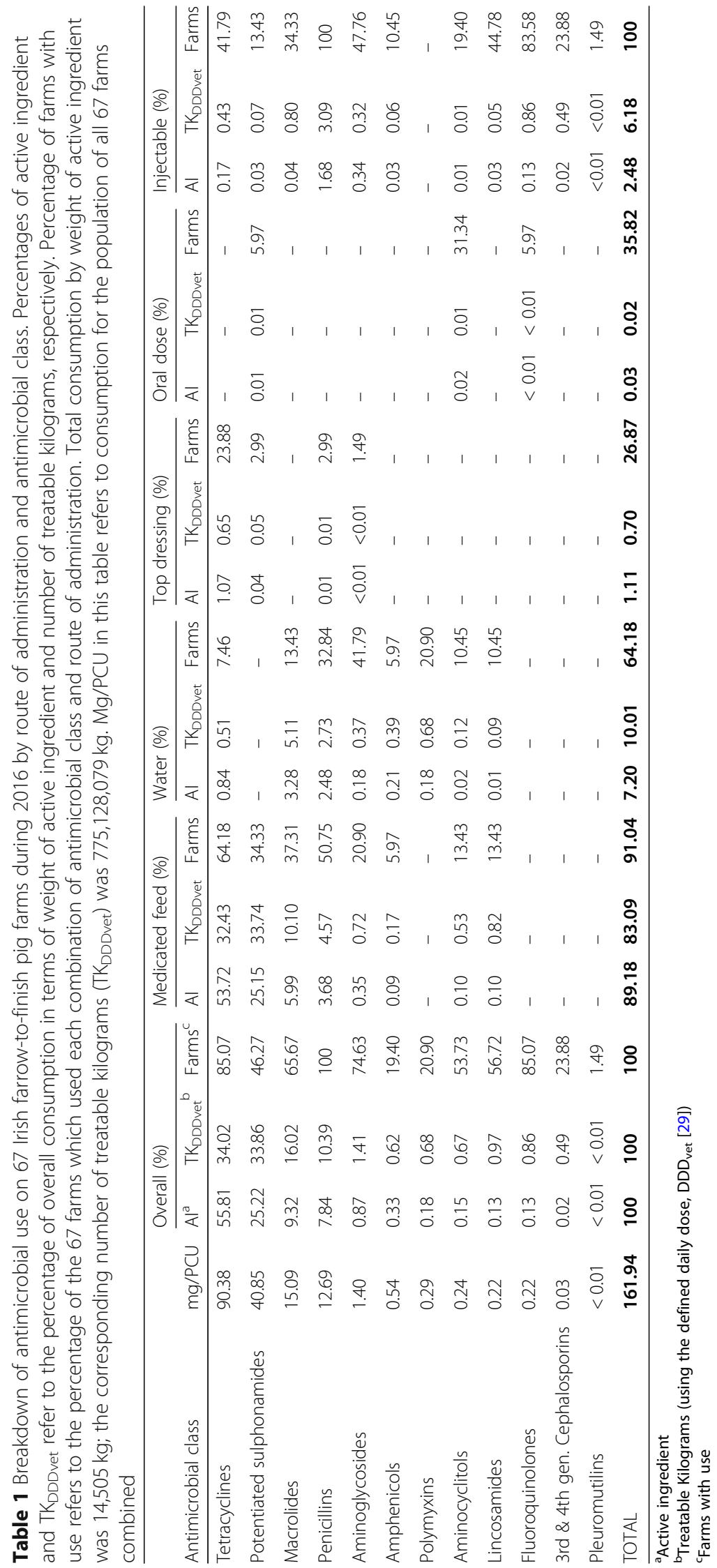




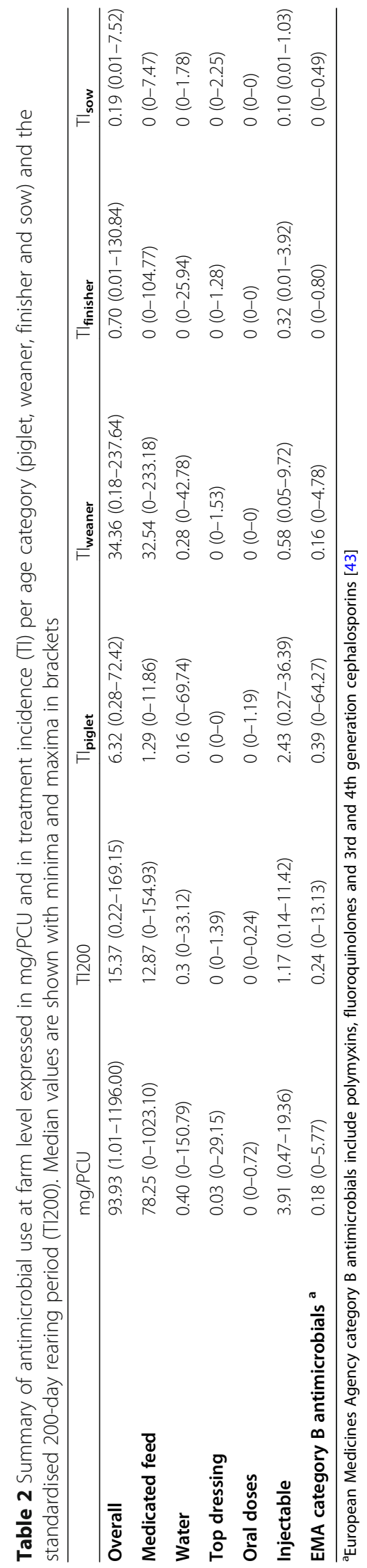




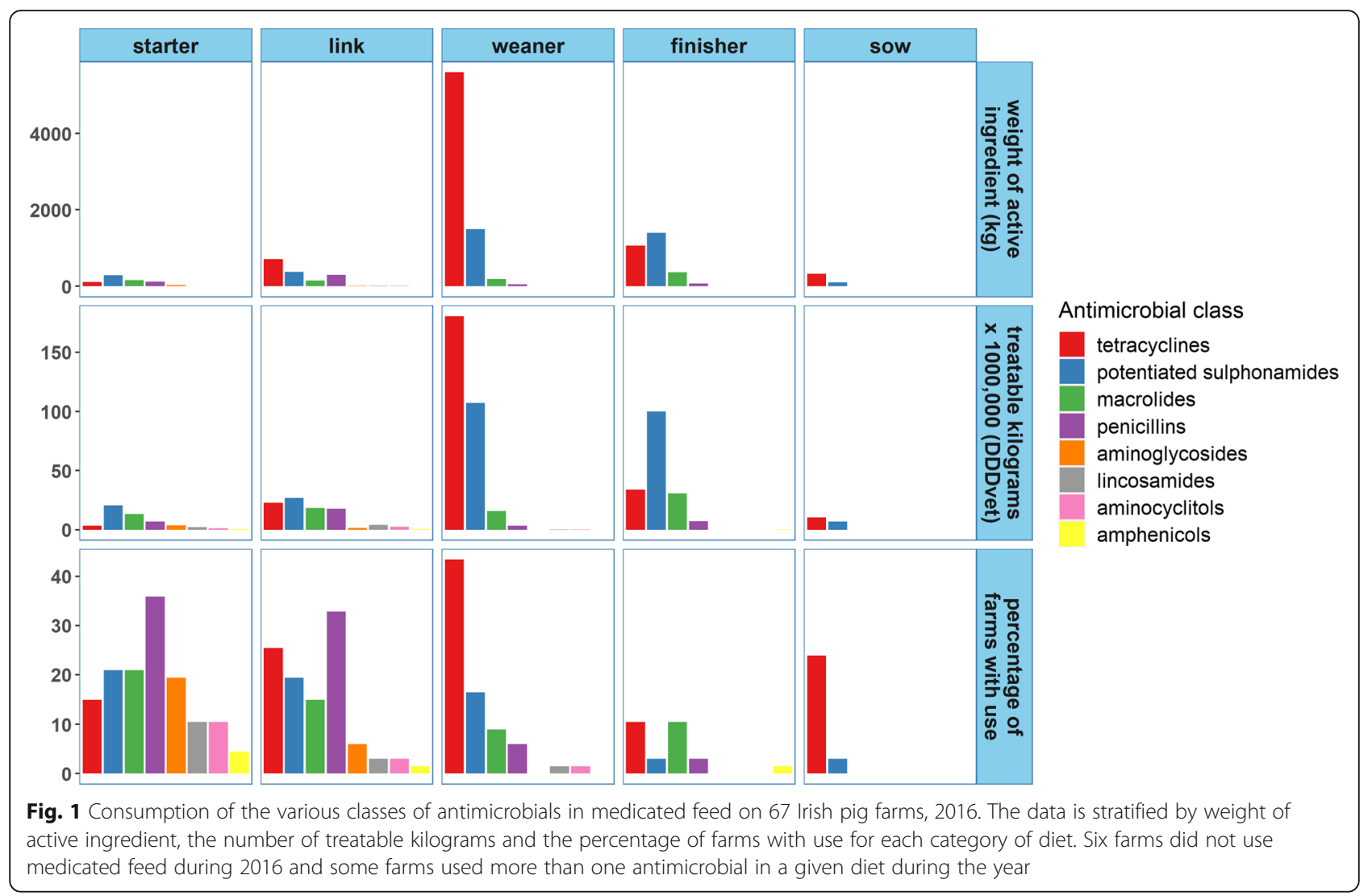

and, that the antimicrobials included often varied from one diet to the next. Twenty-three of the 46 farms routinely medicating both the starter and link diets used the same treatment regime in both diets; of those farms that also medicated the weaner diet, all but one farm used a different antimicrobial.

\section{Antimicrobial use in other routes of administration}

The use of antimicrobials in injectables and oral remedies (other than premix) in weight of active ingredient and treatable kilograms is illustrated in Fig. 3. Fortythree farms (64.2\% of sample) administered antimicrobials in water. This route of administration accounted for $7.2 \%$ of consumption by weight of active ingredient $\left(10 \%\right.$ of $\left.T K_{\text {DDDvet }}\right)$. Macrolides and penicillins were the antimicrobial classes with the highest consumption (see Table 1). The most frequent practice was the administration of the aminoglycoside antimicrobial, apramycin, which was typically provided in drinkers in the farrowing house or post weaning to treat gastroenteritis and was used on $41.8 \%$ of farms. Top dressing, mainly with chlortetracycline, was typically administered to older weaners, finishers or sows, accounted for $1.11 \%$ of AMU by weight $\left(0.7 \%\right.$ of $\left.\mathrm{TK}_{\mathrm{DDDvet}}\right)$ and was used on 16 farms (23.9\% of sample). Oral dosing was recorded on 21 farms
(31.3\% of sample) and accounted $0.03 \%$ of AMU by weight of active ingredient and $0.02 \%$ of $\mathrm{TK}_{\mathrm{DDDvet}}$.

Injectable antimicrobial remedies represented the third most important route of administration. Penicillins were the most used injectable antimicrobial class; all farms used amoxicillin and/or benzylpenicillin (+/- streptomycin). When measured by weight of active ingredient injectables accounted for $2.5 \%$ of all AMU and $6.2 \%$ of TK DDDvet.

\section{Highest priority critically important antimicrobials}

The highest priority critically important antimicrobials (HP CIA), as defined by the World Health Organisation (WHO) [43], used on Irish pig farms included: macrolides; fluoroquinolones (enrofloxacin, marbofloxacin); third generation cephalosporins (ceftiofur); and polymyxins (colistin). The oral macrolides, mainly tylosin but also tilmicosin, represented $9.3 \%$ of all AMU by weight of active ingredient and $15.2 \%$ of $\mathrm{TK}_{\mathrm{DDDvet}}$. The long acting injectable macrolides, tulathromycin and tildipirosin, were not widely used but nevertheless accounted for $12.5 \%$ of injectable $\mathrm{TK}_{\mathrm{DDDvet}}$. The EMA classifies the fluoroquinolones, polymyxins and 3rd and 4th generation cephalosporins as category B antimicrobials ('restrict') and macrolides as category $C$ ('caution') and thus differs from the WHO classification by ranking 


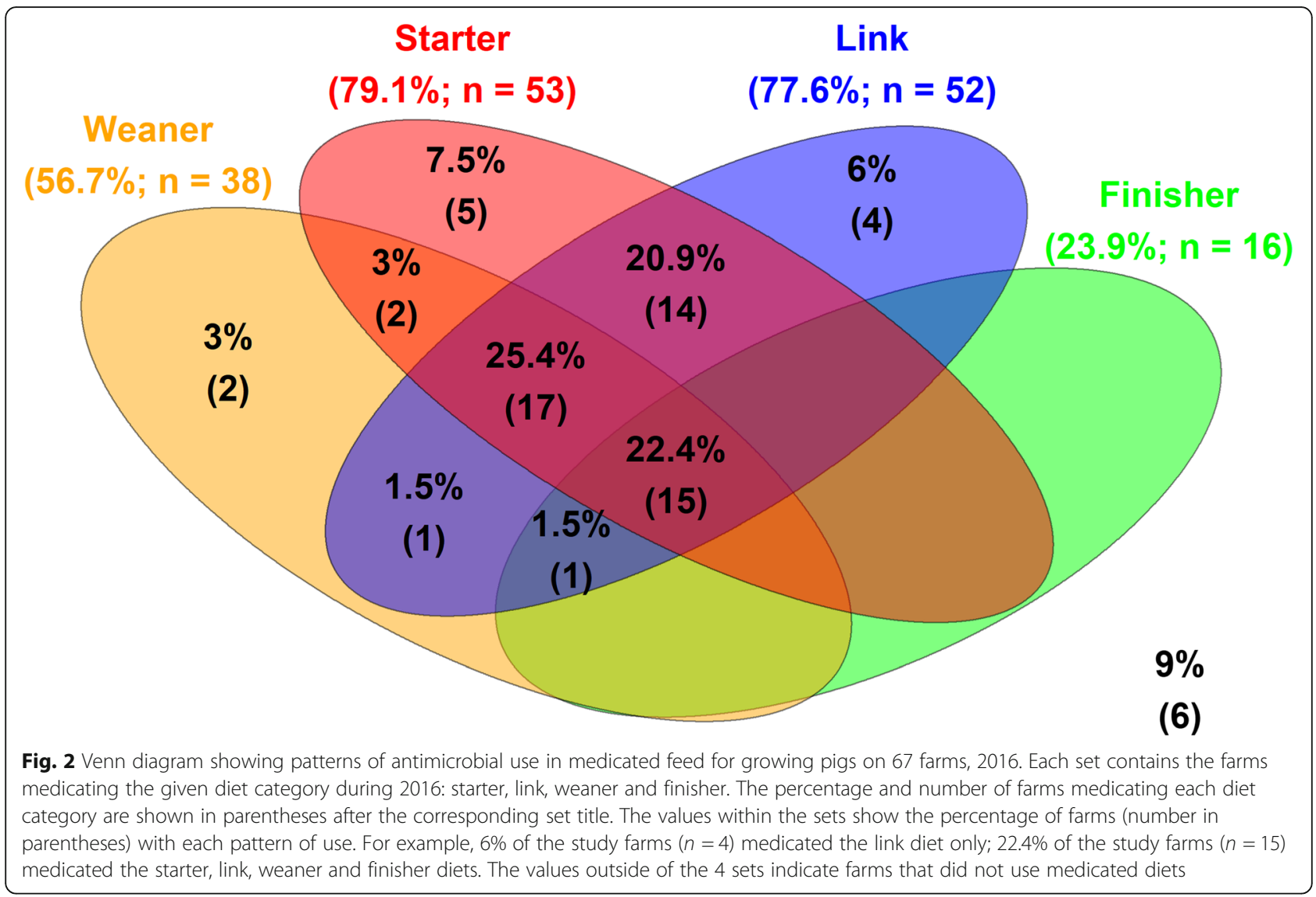

macrolides lower than the other HP CIAs [44]. In terms of overall use, category B antimicrobials represented $0.33 \%$ of the weight of active ingredient used; however, when measured in $\mathrm{TK}_{\mathrm{DDDvet}}$ they accounted for $2 \%$ of consumption (see Table 1). Seven farms (10.4\% of sample) did not use any category B antimicrobials during 2016 while most farms (85.1\% of sample) used fluoroquinolones. The use of category B antimicrobials at farm level is summarised in Table 2. These were mainly administered to suckling piglets and weaned piglets where the highest treatment incidences were observed. In contrast, most farms did not administer category B antimicrobials to finisher pigs or to sows; median TIs in both of these age groups was zero.

\section{Prophylactic use}

In addition to prophylactic AMU in medicated feed, farmers practised other methods of prophylactic treatment. Piglets were injected at birth, processing (iron injection, clipping teeth and tail docking; typically performed during the first week of life) or at weaning on 35 farms (52\% of sample). Amoxicillin was the most commonly used drug ( $n=16 ; 23.8 \%$ of sample) but five other classes of antimicrobial were utilised, notably: ceftiofur on six farms and long acting macrolides on five farms. In the weaner stage, other oral remedies, mainly amoxicillin $(n=4)$, chlortetracycline $(n=2)$ and tylosin $(n=1)$ were used as prophylaxis on seven farms $(10.4 \%$ of sample). In finisher pigs, similar practices were observed on three farms: amoxicillin $(n=1)$; tylosin $(n=2)$. Sows received prophylactic treatments on 11 farms (16.4\% of sample), most frequently in the form of an antimicrobial injection at either farrowing or weaning (eight of 11 farms). Oral chlortetracycline was administered to sows on four of the 11 farms. These practices accounted for a significant proportion of their respective routes of administration, for example prophylactic use of water soluble antimicrobials accounted for $78.8 \%$ of use in this route of administration by weight of active ingredient (for further details see Supplementary Table 2, Additional file 2).

\section{Comparison of AMU in Irish pig production to other countries}

Figure 4 illustrates the comparison between AMU on the Irish sample farms and AMU as derived from the reports of Sweden, Denmark, the Netherlands, France and the UK in 2016. Antimicrobial use for the combined sample population of 67 Irish pig farms was $161.9 \mathrm{mg} /$ PCU and was the second highest of the 6 countries 


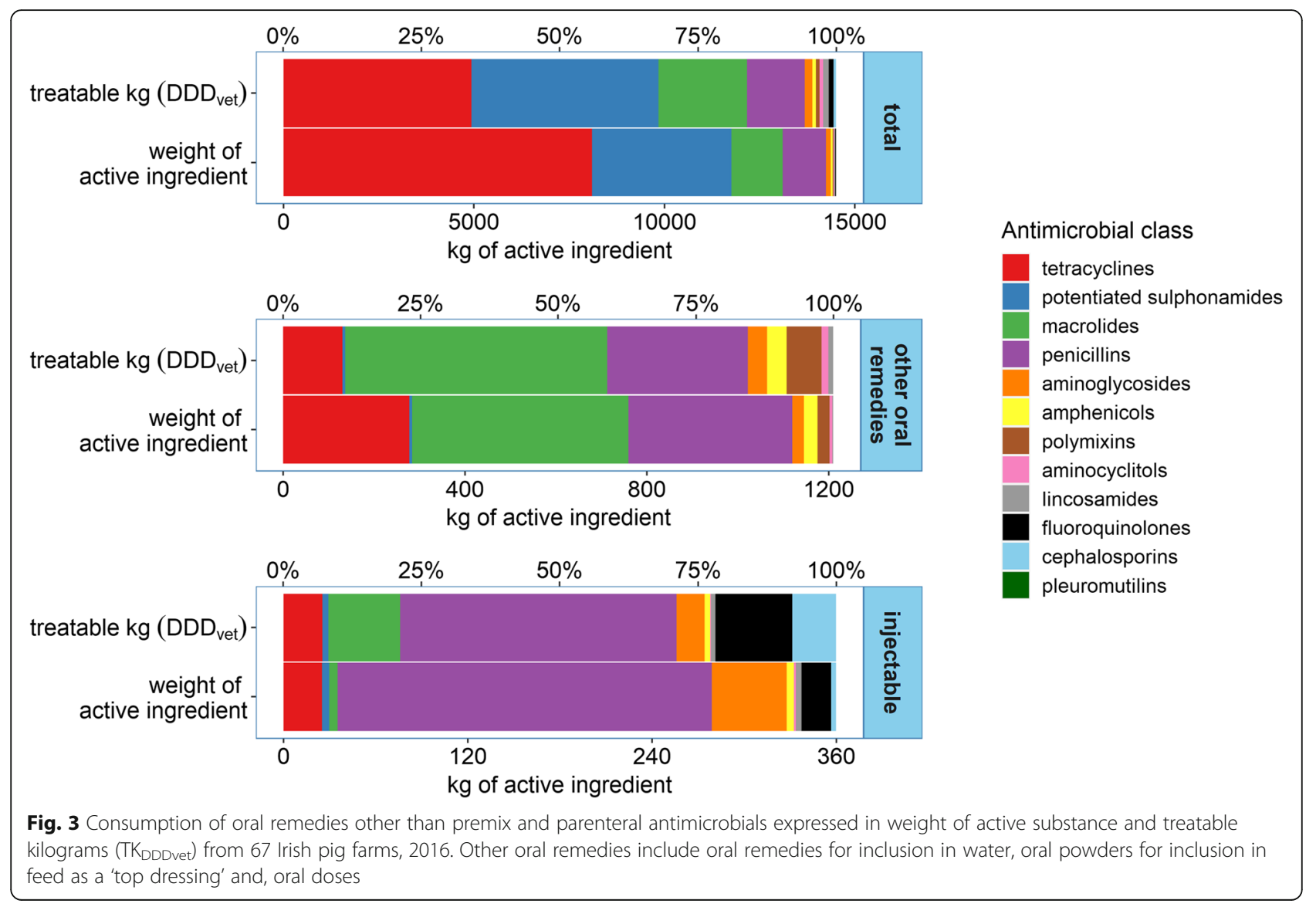

behind the UK. Figure 4 also summarises the comparison of AMU between the Irish sample population and the Danish and Dutch pig production sectors using their respective national indicators. When measured in $\mathrm{mg} /$ PCU, AMU on the Irish pig farms was approximately 3.7 times higher than consumption in both Denmark and the Netherlands. However, when measured in their respective national indicators, DAPD and DDDA $A_{\mathrm{NAT}}$, the relative differences were reduced. For the Irish study sample population, the DAPD was 3.2 times higher than that for Danish pig production while the $\mathrm{DDDA}_{\mathrm{NAT}}$ was 2.5 times higher than Dutch pig production.

\section{Discussion}

This study presents the first detailed data on antimicrobial use in the Irish pig industry. The study sample represented approximately $35 \%$ of the national herd and while it cannot be assumed to be representative of the whole of Irish pig production, the results obtained provide useful insights into antimicrobial use in the industry. Whether measured by weight of active ingredient or in defined daily doses $\left(\mathrm{TK}_{\mathrm{DDDvet}}\right)$ almost all antimicrobials were administered orally and primarily to pigs in the weaner stage of production. This is in agreement with several European studies [17-22, 45] and national reports $[8,9]$. Approximately $103 \mathrm{t}$ of veterinary antimicrobials were sold in Ireland during 2016, based on sales data submitted by Marketing Authorisation Holders to the Health Products Regulatory Authority [46]. Extrapolation of the results from this study suggests that pig production accounts for approximately $40 \%$ of veterinary AMU in Ireland. While this estimate must be interpreted with caution, the data from this study suggest that pigs consume all the oral premix antimicrobials (which accounted for one third of all sales in 2016) but are not significant consumers of the other oral remedies or injectable antimicrobials (which accounted for 33 and $27 \%$ of all sales respectively) [46].

Irish pig farms were also similar to European farms in that so called 'older classes' of antimicrobials such as tetracyclines, potentiated sulphonamides, penicillins, and macrolides were the most used. Macrolides, the third most used class overall, are classified as HP CIA by the WHO but category C ('caution') by the EMA. The difference in ranking between the EMA and WHO results from the EMA's assessment of the importance of this class to veterinary medicine and the fact that for some conditions macrolides represent the only suitable treatment [44]. Colistin, classified as a HP CIA by the WHO [42] and category B ('restrict') by the EMA [44] and 

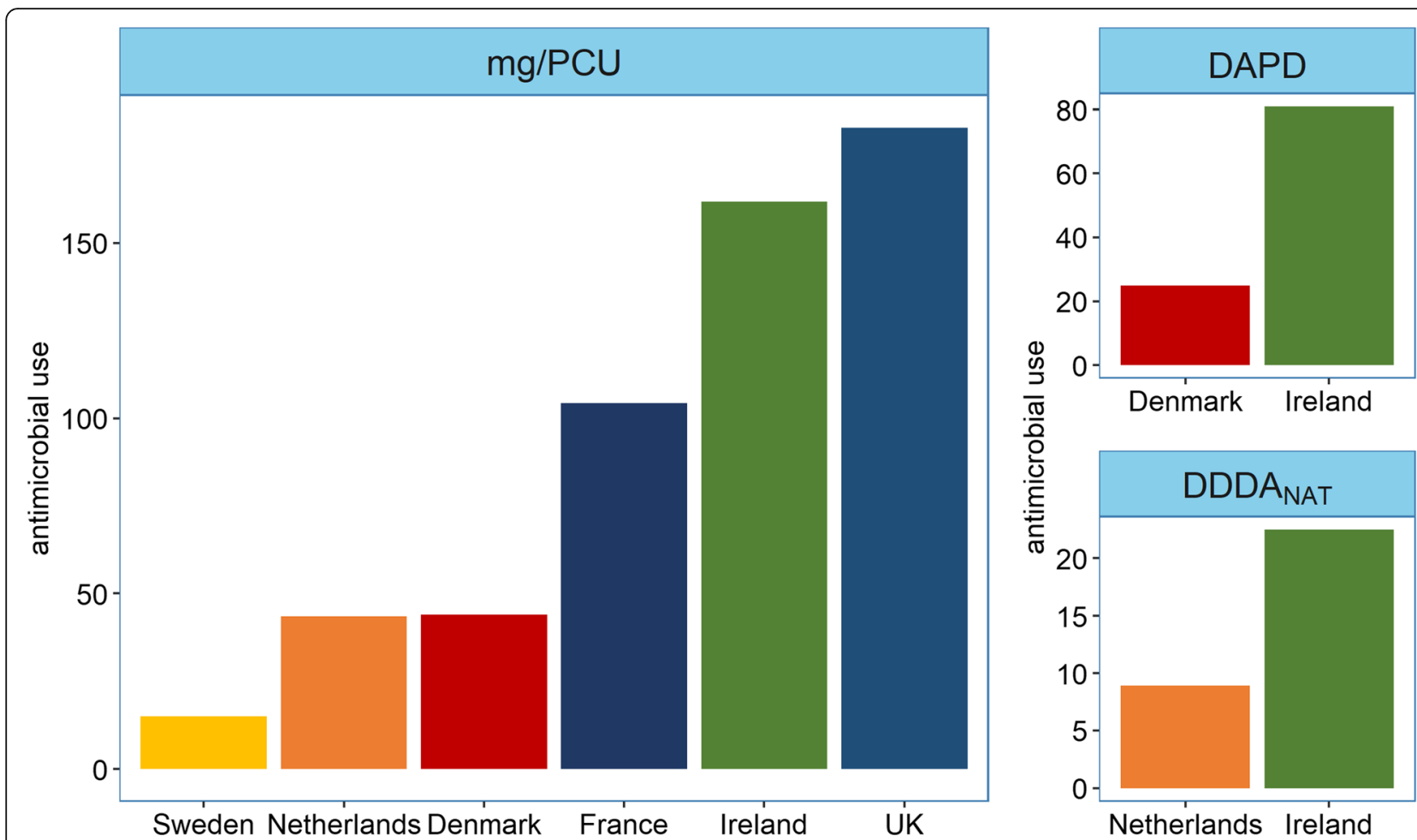

Fig. 4 Comparison of antimicrobial use between the 67 Irish pig farms and 5 European countries in 2016. The large panel shows the comparison of antimicrobial use (AMU) between the Irish sample population and five European countries expressed in mg/PCU [31]. The smaller panels show the comparison of AMU between the Irish sample population and Denmark expressed in DAPD (proportion of animal population in treatment

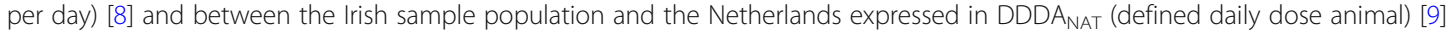

widely used in European pig production [21, 22] was not widely used on Irish farms. Use of cephalosporins and fluoroquinolones (both HP CIA and category B) was also relatively low; however, in countries such as the Netherlands [9] and Denmark [8] where there are restrictions, their use in pig production is negligible or zero. Furthermore, fluoroquinolones along with cephalosporins, constituted $21.8 \%$ of injectable AMU when measured in $\mathrm{TK}_{\mathrm{DDDvet}}$. Since piglet was the age group with the highest exposure to injectable antimicrobials, this implies large proportions of the pig population may receive treatment with these drugs at some point in their life cycle. The widespread use of fluoroquinolones, in particular, is concerning as there is evidence of increasing fluoroquinolone resistance amongst Escherichia coli isolates of porcine origin in Ireland. Data from the European Food Safety Authority (EFSA) monitoring program showed that resistance to ciprofloxacin increased from $2 \%$ in 2015 to $7 \%$ in 2017 [47, 48].

In this study, $95.6 \%$ of all AMU by weight of active ingredient $\left(89.5 \%\right.$ of $\left.\mathrm{TK}_{\text {DDDvet }}\right)$ could be classed as prophylactic. Sarrazin et al. reported increased treatment frequency at 1, 4 and 9 weeks of age which coincided with birth and associated procedures such as teeth clipping and castration, weaning, and transfer to the finisher stage, respectively [22]. Farmers administer prophylactic treatments at these time points to prevent losses associated with expected disease associated with the stresses of handling, movement and dietary changes [49]. Over half of the study farms administered prophylactic antimicrobial treatments during the first week of life and $88.1 \%$ of farms provided antimicrobials in medicated feed at or just after weaning. On $56.7 \%$ of farms, medicated feed was provided in the weaner diet. This is fed at the end of the first weaner stage and throughout the second weaner stage and thus covers another transfer between production stages. Therefore, in contrast to Sarrazin et al., where treatments appeared to be administered at strategic times [22], many farms in Ireland administer antimicrobials at, between and after these times. An important reason for this difference is related to the feeding infrastructure. On most farms, a single feed bin supplies one or more houses containing pigs of different ages. If medicated feed is to be provided to the younger pigs just after transfer, the older pigs must be medicated as well. With regard to the weaner and finisher diets, this has important implications for the overall amounts of antimicrobial consumed since the older and heavier the pig, the more it eats. Similar structural issues were reported on Belgian farms using 
medicated feed [50] and demonstrate the importance of improving antimicrobial delivery systems in efforts to reduce AMU [51].

Quantitative comparisons between studies and national reports are hampered by the use of different indicators of AMU. Use of the $\mathrm{mg} / \mathrm{PCU}$ indicator, developed by ESVAC [31], allowed a comparison of AMU between the sample population in this study and the 2016 national reports of Sweden, Netherlands, Denmark, France and the UK to be made. Antimicrobial consumption for the combined population of Irish farms was the second highest of the six countries compared. Irish AMU was 3.2 and 2.5 times higher than Denmark and the Netherlands, respectively, when measured in their national indicators. The TI200 indicator allowed a comparison of use at farm level between the study farms and the study by Sarrazin and colleagues [22]. Using purchase data for 1 year, the median TI200 for 180 farrowto-finish farms from nine countries in 2015 was 7.1. For the Irish farms in 2016, the median TI200 was 15.3. This comparison should be made with caution. The weaner stage on the Irish study farms was generally longer (median $=9$ weeks, data not shown) than the European farms (median $=6.5$ weeks) [22]. Since most of the AMU is administered in the weaner diet fed to older weaner pigs, the weight at treatment used to calculate the $\mathrm{TI}_{\text {wea- }}$ ner is underestimated. This in turn means that the TI200 is overestimated. Also, the farrow-to-finish system accounts for almost all pig production in Ireland [26], and in this regard, the study is representative of the whole industry. In other countries, where specialised weaner and finisher farms are more prominent [26] measuring AMU on farrow-to-finish farms may not be representative. Some studies have found that AMU is higher in finisher pigs on specialised finisher farms than on farrowfinish farms and suggest the stress of transport and mixing pigs from different sources as a possible explanation $[12,19,52]$. Nevertheless, these results show that AMU in Irish pig production compared unfavourably to some of its European peers in 2016. It should be noted, however, that comparable data from many other countries is not yet available and that those countries with AMU data are, in general, further into their respective 'action plans' against antimicrobial resistance than Ireland.

These findings highlight the need to reduce AMU in Irish pig production. New EU regulations governing antimicrobial use and medicated feed, which come into effect in 2022, will prevent prophylactic AMU and restrict metaphylactic group treatments as well as the use of CIAs $[28,53]$. This will require a significant shift in behavioural and management practices related to AMU on Irish pig farms, particularly with regard to routine prophylactic use in feed medication. A pilot study carried out on an Irish farm suggests this can be achieved without impacting welfare or performance [54, 55] and as an example, if AMU in medicated feed in the weaner, finisher and sow diets were removed from the current study, total AMU for the sample population would reduce to $43.1 \mathrm{mg} / \mathrm{PCU}$ which is just below the levels for Denmark and the Netherlands. It should be noted that several farms in the study were already at or below this level of AMU (see Fig. 2); six farms (9\% of sample) did not use any medicated feed and seven (10.4\% of sample) did not use any category B antimicrobials. The risk factors for AMU on Irish pig farms have not been studied. However, recent work has identified respiratory disease as a significant problem on Irish pig farms [56] and this may explain the high use of antimicrobials in the weaner diets fed to 2nd stage weaner pigs. Also, internal biosecurity on Irish pig farms is lower than in other European countries [57]. Improved biosecurity was shown to aid in reducing AMU on Belgian pig farms [58] and a recent initiative launched by Animal Health Ireland has made biosecurity audits available to all Irish pig farms. ${ }^{2}$ Other initiatives such as measuring AMU, increased education and the promotion of responsible use guidelines, which are all part of iNAP [3], have had success in reducing AMU in pig production in other countries [59]. The recent launch of the 'national AMU database for pigs' by the Department of Agriculture Food and the Marine has fulfilled a key priority of iNAP and will allow for the monitoring of AMU in Irish pig production and for the assessment of the impact of AMU reduction strategies [60].

The main limitation of this study is that the data was collected from a convenience sample of farms and thus may not be representative of the entire population. The farms used in this study had originally volunteered to take part in a survey investigating biosecurity and management practices and could represent farms with better practices than the rest of the population which could have introduced a selection bias. Nevertheless, the study population represented around 35\% of the national herd and therefore a significant proportion of the industry. Collecting AMU data in the field presents challenges. Records are not always kept $[20,22]$ and antimicrobial preparations are often used in different age groups without records of which pigs they were allocated to [22] and, therefore, assumptions and imputations had to be made in some instances. There were similar challenges in this study. Where records were incomplete, estimations of AMU were given by the farmer and could be subject to recall bias and intervention bias (where the farmer deliberately under reports AMU). Since the majority of AMU was via medicated feed and is an important part of farm management, the risk of recall bias is considered to be low for this route of administration.

\footnotetext{
${ }^{2}$ http://animalhealthireland.ie/?page_id $=18234$
} 
Overall, approximately $96 \%$ ( $94 \%$ of $\left.\mathrm{TK}_{\mathrm{DDDvet}}\right)$ of the antimicrobials used could be accurately assigned to the correct age group.

\section{Conclusions}

Antimicrobial use on Irish pig farms is characterised by a high proportion of prophylactic use, primarily delivered using medicated feed and mainly administered to pigs in the post weaning production stages. These patterns of use are similar to those reported in other European studies although the amounts used are higher than some countries such as Sweden, Denmark and the Netherlands. This study confirms that pig production is an important consumer of veterinary antimicrobials, accounting approximately for $40 \%$ of AMU in Ireland in 2016; and reinforces the need to reduce AMU. The identification of the pattern of use with the highest impact on consumption, the provision of medicated feed to weaner pigs, suggest that efforts to understand the reasons for this and promote better health among weaner pigs will be of benefit.

\section{Supplementary information}

Supplementary information accompanies this paper at https://doi.org/10. 1186/s40813-020-00166-y.

\section{Additional file 1: Supplementary Methods \\ Additional file 2: Supplementary Table 1. Breakdown of} antimicrobial use by stage of production. Supplementary Figure 1. Numbers of antimicrobials used in medicated feed in diets for growing pigs on 67 Irish pig farms during 2016. Supplementary Table 2. Prophylactic AMU in oral remedies other than premix and injectable preparations.

\section{Abbreviations \\ AMU: Antimicrobial use; CIA: Critically important antimicrobial; DAPD: Proportion of animal population in treatment per day; DDD: Defined daily dose; $\mathrm{DDD}_{\text {vet: }}$ : Defined daily dose (as defined by the EMA); $D_{\text {DDDA }}$ T: Defined daily dose animal (to define national AMU in the Netherlands); EMA: European Medicines Agency; ePM: E-Profit Monitor; ESVA C: European Surveillance of Veterinary Antimicrobial Consumption; HP CIA: Highest priority critically important antimicrobial; iNAP: Ireland's National Action Plan against Antimicrobial Resistance; PCU: Population correction unit: TI: Treatment incidence; TK: Treatable kilograms; UK: United Kingdom; WHO: World Health Organisation}

\section{Acknowledgements}

The authors would like to thank the participating farmers and their private veterinary practitioners for their cooperation with this study. The authors would also like to thank the advisors in the Teagasc Pig Development Department for their advice and assistance with farm recruitment, farm visits and data collection.

\section{Authors' contributions}

LON drafted the manuscript and performed the data analysis and data visualisation. EGM, JG and FCL were responsible for the conceptualisation and design of the study, and for funding acquisition. LON, MRC, JACD, GM and EGM performed the data collection in the field. LON, MRC, FCL and EGM reviewed and edited the manuscript. All authors read and approved the final draft.

\section{Funding}

The current study was conducted within the AMURAP project (Antimicrobial Use and Resistance in Animal Production) which investigates AMU and AMR in the Irish pig and poultry industries. This project is funded by the Irish Department of Agriculture Food and the Marine (grant reference number 15 $S$ 676). The funders had no role in the study design, data collection and analysis, decision to publish, or preparation of the manuscript.

\section{Availability of data and materials}

The datasets used and/or analysed during the current study are available from the corresponding author on reasonable request.

\section{Ethics approval and consent to participate}

The participating farmers gave informed written consent for the use of their data in this study. This research did not involve the use of animal subjects.

Thus, formal approval by an ethics committee was not required under Irish regulations.

\section{Consent for publication}

Not applicable.

\section{Competing interests}

The authors declare that they have no competing interests.

\section{Author details}

'Pig Development Department, Teagasc, The Irish Food and Agriculture Authority, Moorepark, Fermoy, Co Cork, Ireland. ${ }^{2}$ School of Veterinary Medicine, University College Dublin, Belfield, Dublin 4, Ireland. Irish Equine Centre, Johnstown, Co Kildare, Ireland. ${ }^{4}$ Pig Development Department, Teagasc, The Irish Food and Agriculture Authority, Oakpark, Carlow, Co Carlow, Ireland.

Received: 12 August 2020 Accepted: 21 August 2020

Published online: 12 October 2020

\section{References}

1. World Health Organisation. Global Action Plan on Antimicrobial Resistance (2015) ISBN 9789241509763 Available at: https://apps.who.int/iris/ bitstream/handle/10665/193736/9789241509763_eng.pdf?sequence=1 (accessed on 2 April 2020)

2. European Commission. A European one health action plan against antimicrobial resistance (AMR) (2017) Available at: https://ec.europa.eu/ health/amr/sites/health/files/antimicrobial_resistance/docs/amr_2017_ action-plan.pdf (accessed on 2 April 2020).

3. Department of Health. Ireland's National Action Plan on Antimicrobial Resistance 2017-2020. (iNAP). (2017) Available at: https://www.agriculture. gov.ie/media/migration/animalhealthwelfare/amr/inap/ IrelandNationalActionPlanAntimicrobialResistance030818.pdf (accessed on 2 Dec 2019).

4. EMA (European Medicines Agency) and EFSA (European Food Safety Authority). EMA and EFSA Joint Scientific Opinion on measures to reduce the need to use antimicrobial agents in animal husbandry in the European Union, and the resulting impacts on food safety (RONAFA). EFSA J. 2017; 15(1):4666-245. https://doi.org/10.2903/j.efsa.2017.4666 [EMA/CVMP/570771/ 2015].

5. Chantziaras I, Boyen F, Callens B, Dewulf J. Correlation between veterinary antimicrobial use and antimicrobial resistance in food-producing animals: a report on seven countries. J Antimicrob Chemother. 2014;69(3):827-34. https://doi.org/10.1093/jac/dkt443.

6. Marshall B, Levy S. Food animals and antimicrobials: impacts on human health. Clin Microbiol Rev. 2011;24(4):718-33. https://doi.org/10.1128/CMR. 00002-11

7. Vieira AR, Collignon P, Aarestrup FM, McEwen SA, Hendriksen RS, Hald T, et al. Association between antimicrobial resistance in Escherichia coli isolates from food animals and blood stream isolates from humans in Europe: an ecological study. Foodborne Pathog Dis. (2011) 8(12):1295-1301. DOl: https://dx.doi.org/https://doi.org/10.1089/fpd.2011.0950.

8. DANMAP (Danish Integrated Antimicrobial Resistance Monitoring and Research Programme). DANMAP 2018. Use of antimicrobial agents and occurrence of antimicrobial resistance in bacteria from food animals, food and humans in Denmark. ISSN 1600-2032 (2019) Available at: https://www. 
danmap.org/-/media/arkiv/projekt-sites/danmap/danmap-reports/danmap-2 018/danmap_2018.pdf?la=en (accessed on 1 April 2020).

9. The Netherlands Veterinary Medicines Institute, 2019. Usage of antibiotics in agricultural livestock in the Netherlands in 2018. Trends and benchmarking of livestock farms and veterinarians. https://cdn.i-pulse.nl/ autoriteitdiergeneesmiddelen/userfiles/Publications/2018-def-rapport1.pdf (accessed on 2 April 2020).

10. Belvet-SAC. Belgian Veterinary Surveillance of Antibacterial Consumption National consumption report2018. (2019) Available at: https://belvetsac. ugent.be/BelvetSAC_report_2018.pdf (accessed on 2 April 2020).

11. AACTING-network. Systems for Quantification of Antimicrobial Usage. Available online at: http://www.aacting.org/monitoring-systems/ (accessed 27 March 2020).

12. Hemme M, Ruddat I, Hartmann M, Werner N, van Rennings L, Käsbohrer A, et al. Antibiotic use on German pig farms - a longitudinal analysis for 2011 , 2013 and 2014. PLoS One. 2018;13(7):e0199592. https://doi.org/10.1371/ journal.pone.0199592.

13. Dunlop RH, McEwen SA, Meek AH, Black WD, Clarke RC, Friendship RM. Individual and group antimicrobial usage rates on 34 farrow-to-finish swine farms in Ontario, Canada. Prev Vet Med. 1998;34(4):247-64.

14. Rajić A, Reid-Smith R, Deckert AE, Dewey CE, McEwen SA. Reported antibiotic use in 90 swine farms in Alberta. Can Vet J. 2006;47(5):446-52.

15. Trauffler M, Griesbacher A, Fuchs K, Köfer J. Antimicrobial drug use in Austrian pig farms: plausibility check of electronic on-farm records and estimation of consumption. Vet Rec. 2014;175(16) vetrec-2014-102520. https://doi.org/10.1136/vr.102520.

16. Chauvin C, Beloeil P-AA, Orand J-PP, Sanders P, Madec F. A survey of grouplevel antibiotic prescriptions in pig production in France. Prev Vet Med. 2002;55(2):109-20. https://doi.org/10.1016/s0167-5877(02)00091-0.

17. Hémonic A, Chauvin C, Delzescaux D, Verliat F, Corrégé I, industry FWG 'antimicrobials in the swine. Reliable estimation of antimicrobial use and its evolution between 2010 and 2013 in French swine farms. Porcine Health Manag. 2018;4:8. https://doi.org/10.1186/s40813-018-0084-7.

18. Moreno M. Survey of quantitative antimicrobial consumption in two different pig finishing systems. Vet Rec. 2012;171(13):325. https://doi.org/10. 1136/vr.100818

19. Moreno MA. Survey of quantitative antimicrobial consumption per production stage in farrow-to-finish pig farms in Spain. Vet Rec Open 2014; 1(1):e000002. http://dx.doi.org/https://doi.org/10.1136/vropen-2013-000002.

20. Callens B, Persoons D, Maes D, Laanen M, Postma M, Boyen F, et al. Prophylactic and metaphylactic antimicrobial use in Belgian fattening pig herds. Prev Vet Med. 2012;106(1):53-62. https://doi.org/10.1016/j.prevetmed. 2012.03.001

21. Sjölund M, Postma M, Collineau L, Lösken S, Backhans A, Belloc C, et al. Quantitative and qualitative antimicrobial usage patterns in farrow-to-finish pig herds in Belgium, France, Germany and Sweden. Prev Vet Med. 2016; 130:41-50. https://doi.org/10.1016/j.prevetmed.2016.06.003.

22. Sarrazin S, Joosten P, Gompel LV, Luiken RECE, Mevius DJ, Wagenaar JA, et al. Quantitative and qualitative analysis of antimicrobial usage patterns in 180 selected farrow-to-finish pig farms from nine European countries based on single batch and purchase data. J Antimicrob Chemother. 2019;74(3): 807-16. https://doi.org/10.1093/jac/dky503.

23. Central Statistics Office (CSO). Pig Survey June 2019 (2019). Available at https://www.cso.ie/en/releasesandpublications/er/ps/pigsurveyjune2019/ (accessed on 11 May 2020).

24. Central Statistics Office (CSO). Livestock slaughterings December 2019 (2020). Available at https://www.cso.ie/en/releasesandpublications/er/ls/ livestockslaughteringsdecember2019/ (accessed 11 May 2020).

25. Food Safety Authority of Ireland. Report of the Scientific Committee of the Food Safety Authority of Ireland Potential for Transmission of Antimicrobial Resistance in the Food Chain. Dublin: FSAl; 2015. p. 62.

26. Marquer $P$, Rabade, T., Forti, R. Pig farming in the European Union: considerable variations from one Member State to another. Eurostat: Statistics in focus 2014; ISSN:2314-9647; Catalogue number: KS-SF-14-015EN-N. https://ec.europa.eu/eurostat/statistics-explained/index.php?title= Archive:Pig_farming_sector_-_statistical_portrait_2014.

27. European Medicines Agency. Guidance on collection and provision of national data on antimicrobial use by animal species/categories. (2018) Available at: https://www.ema.europa.eu/en/documents/scientific-guideline/ guidance-collection-provision-national-data-antimicrobial-use-animalspecies/categories_en.pdf (accessed on 20 March 2020).
28. Regulation (EU) 2019/4 of the European Parliament and of the Council of 11 December 2018 on the manufacture, placing on the market and use of medicated feed, amending Regulation (EC) No 183/2005 of the European Parliament and of the Council and repealing Council Directive 90/167/EEC (Text with EEA relevance) Official Journal of the European Union. 2019;L4:123. ELI: http://data.europa.eu/eli/reg/2019/4/oj .

29. European Medicines Agency. Defined daily doses for animals (DDDvet) and defined course doses for animals (DCDvet) European Surveillance of Veterinary Antimicrobial Consumption (ESVAC). (2016) Available at: https:// www.ema.europa.eu/en/documents/other/defined-daily-doses-animalsdddvet-defined-course-doses-animals-dcdvet-european-surveillance_en.pdf (accessed on 20 March 2020).

30. Postma M, Sjölund M, Collineau L, Lösken S, Stärk KD, Dewulf J, et al. Assigning defined daily doses animal: a European multi-country experience for antimicrobial products authorized for usage in pigs. J Antimicrob Chemother. 2015;70(1):294-302. https://doi.org/10.1093/jac/dku347.

31. European Medicines Agency. Trends in the sales of veterinary antimicrobial agents in nine European countries. (2011) Available at https://www.ema. europa.eu/documents/report/trends-sales-veterinary-antimicrobial-agentsnine-european-countries_en.pdf (accessed on 2 Dec 2019).

32. Timmerman T, Dewulf J, Catry B, Feyen B, Opsomer G, de Kruif A, et al. Quantification and evaluation of antimicrobial drug use in group treatments for fattening pigs in Belgium. Prev Vet Med. 2006;74(4):251-63. https://doi. org/10.1016/j.prevetmed.2005.10.003.

33. Swedres-Svarm. Consumption of antibiotics and occurrence of resistance in Sweden. Solna/Uppsala ISSN 1650-6332 (2016). Available at: https://www.sva.se/media/1xocwfe3/swedres_svarm2016.pdf (accessed on 20 Nov 2019).

34. The Netherlands Veterinary Medicines Institute. Usage of Antibiotics in Agricultural Livestock in the Netherlands in 2016. Trends and benchmarking of livestock farms and veterinarians. (2017) Available at: https://cdn.i-pulse. $\mathrm{nl} /$ autoriteitdiergeneesmiddelen/userfiles/Publications/engels-defrapportage-2016-deel-1-en-2-22-09-2017.pdf (accessed on 20 Nov 2019).

35. DANMAP (Danish Integrated Antimicrobial Resistance Monitoring and Research Programme). DANMAP 2016. Use of antimicrobial agents and occurrence of antimicrobial resistance in bacteria from food animals, food and humans in Denmark. ISSN 1600-2032 (2017) https://www.danmap. org/-/media/arkiv/projekt-sites/danmap/danmap-reports/danmap-2016/ danmap_2016_web.pdf (accessed on 20 Nov 2019).

36. French Agency for Food, Environmental and Occupational Health \& Safety (ANSES) - French Agency for Veterinary Medicinal Products (ANMV). Sales survey of veterinary medicinal products containing antimicrobials in France in 2016. (2017) Available at: https://www.anses.fr/en/system/files/ANMV-RaAntibiotiques2016EN.pdf (accessed on 20 Nov 2019).

37. European Medicines Agency, European Surveillance of Veterinary Antimicrobial Consumption. 'Sales of veterinary antimicrobial agents in 30 European countries in 2016'. (2018) Available at: https://www.ema.europa. eu/en/documents/report/sales-veterinary-antimicrobial-agents-30-europeancountries-2016-trends-2010-2016-eighth-esvac_en.pdf (EMA/275982/2018) Available at: (accessed on 20 Nov 2019).

38. UK-VARSS. UK Veterinary Antibiotic Resistance and Sales Surveillance Report (UK-VARSS 2018). Veterinary Medicines Directorate. (2019) Available at: https://assets.publishing.service.gov.uk/government/uploads/system/ uploads/attachment_data/file/842678/PCDOCS-_1705145-v1-UK-VARSS_201 8_Report_2019_FINAL_v2.pdf (accessed on 20 Nov 2019).

39. R Core Team. R: A language and environment for statistical computing. Vienna: R Foundation for Statistical Computing; 2017. https://www.R-project.org/.

40. Wickham H. ggplot2: Elegant Graphics for Data Analysis. New York: Springer-Verlag; 2016. https://ggplot2.tidyverse.org.

41. Hanbo Chen (2018). VennDiagram: generate high-resolution Venn and Euler plots. R package version 1.6.20. https://CRAN.R-project.org/package= VennDiagram

42. Central Statistics Office (CSO). Pig Survey June 2016. (2016) Available at https://www.cso.ie/en/releasesandpublications/er/ps/pigsurveyjune2016/ (accessed on 1 April 2020).

43. World Health Organization (WHO). Critically Important Antimicrobials for Human Medicine-6th Revision 2018. 2019. https://apps.who.int/iris/ bitstream/handle/10665/312266/9789241515528-eng.pdf?ua=1 (accessed on 1 April 2020).

44. European Medicines Agency. Categorisation of antibiotics for use in animals for prudent and responsible use. (2019). Available at: https://www.ema. 
europa.eu/en/documents/report/categorisation-antibiotics-use-animalsprudent-responsible-use_en.pdf (accessed on 2 Feb 2020).

45. Echtermann T, Muentener C, Sidler X, Kümmerlen D. Antimicrobial Drug Consumption on Swiss Pig Farms: A Comparison of Swiss and European Defined Daily and Course Doses in the Field. Front Vet Sci. 2019;6:240. https://doi.org/10.3389/fvets.2019.00240.

46. Health Products Regulatory Authority. Report on consumption of veterinary antibiotics in Ireland during 2016. (2017). Available at: https://www.hpra.ie/ docs/default-source/default-document-library/report-on-consumption-ofveterinary-antibiotics-in-ireland-during-2016367b0a2697826eee9b55 ff00008c97d0.pdf?sfursn=0 (accessed on 2 Feb 2020).

47. EFSA (European Food Safety Authority) and ECDC (European Centre for Disease Prevention and Control). The European Union summary report on antimicrobial resistance in zoonotic and indicator bacteria from humans, animals and food in 2015. EFSA J. 2017;15(2):4694-212. https://doi.org/10. 2903/j.efsa.2017.4694.

48. EFSA (European Food Safety Authority) and ECDC (European Centre for Disease Prevention and Control), 2019. The European Union summary report on antimicrobial resistance in zoonotic and indicator bacteria from humans, animals and food in 2017. EFSA J (2019);17(2):5598, 5278 pp. https://doi.org/https://doi.org/10.2903/j.efsa.2019.5598.

49. Schwarz S, Kehrenberg C, Walsh TR. Use of antimicrobial agents in veterinary medicine and food animal production. Int J Antimicrob Agents. 2001;17(6):431-7. https://doi.org/10.1016/s0924-8579(01)00297-7.

50. Vandael F, Filippitzi M-E, Dewulf J, Daeseleire E, Eeckhout M, Devreese M, et al. Oral group medication in pig production: characterising medicated feed and drinking water systems. Vet Rec. 2019;185(13) vetrec-2019-105495. https://doi.org/10.1136/vr.105495.

51. Ferran AA, Roques BB. Can oral group medication be improved to reduce antimicrobial use? Vet Rec. 2019;185(13):402. https://doi.org/10.1136/vr.l5656.

52. van der Fels-Klerx HJ, Puister-Jansen LF, van Asselt ED, Burgers SLGE. Farm factors associated with the use of antibiotics in pig production. J Anim Sci. (2011) ;89(6):1922-1929. https://dx.doi.org/https://doi.org/10.2527/jas.20103046.

53. Regulation (EU) 2019/6 of the European Parliament and of the Council of 11 December 2018 on veterinary medicinal products and repealing Directive 2001/82/EC (Text with EEA relevance) Official Journal of the European Union. 2019;L4:43-167. ELl: http://data.europa.eu/eli/reg/2019/6/oj.

54. Diana A, Manzanilla EG, Calderón Díaz JA, Leonard FC, Boyle LA. Do weaner pigs need in-feed antibiotics to ensure good health and welfare? PLoS One. 2017;12(10):e0185622. https://doi.org/10.1371/journal.pone.0185622.

55. Diana A, Boyle LA, Leonard FC, Carroll C, Sheehan E, Murphy D, et al. Removing prophylactic antibiotics from pig feed: how does it affect their performance and health? BMC Vet Res. 2019;15(1):67. https://doi.org/10. 1186/s12917-019-1808-x.

56. Rodrigues da Costa M. (2018) Evaluation of current feeding and management practices in Irish pig production and future strategies for improvement. [dissertation/PhD thesis] Barcelona: Universitat Autònoma de Barcelona. http://hdl.handle.net/10803/666618.

57. Rodriques da Costa M, Gasa J, Calderón Díaz JA, Postma M, Dewulf J, McCutcheon G, et al. Using the Biocheck.UGent ${ }^{\text {TM }}$ scoring tool in Irish farrow-to-finish pig farms: assessing biosecurity and its relation to productive performance. Porcine Health Manag. (2019);5(1). https://dx.doi. org/https://doi.org/10.1186/s40813-018-0113-6.

58. Postma M, Vanderhaeghen W, Sarrazin S, Maes D, Dewulf J. Reducing antimicrobial usage in pig production without jeopardizing production parameters. Zoonoses Public Health. 2017;64(1):63-74. https://doi.org/10. 1111/zph.12283

59. Speksnijder D, Mevius D, Bruschke C, Wagenaar J. Reduction of veterinary antimicrobial use in the Netherlands. The Dutch success model. Zoonoses Public Health. 2015;62(s1):79-87. https://doi.org/10.1111/zph.12167.

60. National AMU database for pigs. aacting.org. 2019. Available at: https:// aacting.org/matrix/national-amu-database-for-pigs/?lid=1447 (accessed on 2 May 2020).

\section{Publisher's Note}

Springer Nature remains neutral with regard to jurisdictional claims in published maps and institutional affiliations.

\section{Ready to submit your research? Choose BMC and benefit from:}

- fast, convenient online submission

- thorough peer review by experienced researchers in your field

- rapid publication on acceptance

- support for research data, including large and complex data types

- gold Open Access which fosters wider collaboration and increased citations

- maximum visibility for your research: over $100 \mathrm{M}$ website views per year

At $\mathrm{BMC}$, research is always in progress.

Learn more biomedcentral.com/submissions 